\title{
Los ministerios en las primeras comunidades cristianas según el Nuevo Testamento
}

\author{
Ministries in the Early Christian Communities \\ according to the New Testament
}

ROMANO PENNA

Pontificia Università Lateranense (Roma)

romano.penna@gmail.com

Fecha de recepción: 5/6/2021

Fecha de aceptación: 15/7/2021

https://doi.org/10.52039/seminarios.v66i228.375

RESUMEN: El Jesús histórico, con la elección de los Doce, ya había pensado en quiénes compartirían su responsabilidad evangelizadora. Pero fueron después las iglesias pospascuales en sus diferentes configuraciones (judeocristiana, paulina, joánica) las que expresaron con cierta variedad de denominaciones las funciones de gobierno en su seno, así como la proyección misionera hacia el exterior. Un dato común es que los ministerios se entienden como diakonía al servicio de la comunidad, y en las iglesias paulinas incluso las mujeres tienen una función destacada. Además, ningún ministerio es considerado como sacerdotal, mientras que toda la comunidad cristiana sí lo es. Un factor común es la fraternidad que une, no sólo a los bautizados, sino también a los distintos responsables eclesiales.

Palabras ClaVE: Apóstoles, Evangelio, Comunidad, Responsabilidad pastoral, Servicio, Fraternidad

ABSTRACT: The historical Jesus chose the Twelve to share his evangelising mission. But it was the post-Easter churches in their different configurations (Judeo-Christian, Pauline, Johannine) that expressed, with a certain variety of denominations, the functions of government within them, as well as of missionary work outside. A common feature is that ministries are understood as diakonia in the service of the community, and in the Pauline churches women also have a prominent function. Moreover, no ministry is qualified as priestly, whereas the whole Christian community qualifies as such. A common factor is the fraternity that unites together, not only the baptised, but also the various church leaders.

KeYwords: Apostles, Gospel, Community, Pastoral Responsibility, Service, Fraternity 


\section{PREÁMBULO}

La comunidad cristiana tiene desde el principio su propia estructura. De hecho, toda comunidad debe tenerla pues, de lo contrario, como dice Aristóteles, sería singularmente autónoma «como una bestia o un dios» ${ }^{1}$. Esto es cierto no sólo para las grandes entidades políticas, sino también para los pequeños grupos, como las comunidades judías de los esenios y, en particular, de Qumrán ${ }^{2}$. Al principio, el movimiento cristiano se manifestó públicamente en forma de pequeñas iglesias locales: comenzando desde Jerusalén hasta Roma y pasando por las ciudades de Antioquía de Siria, Éfeso, Tesalónica, Filipos, Corinto, cada una de las comunidades cristianas contaban apenas con algunas decenas de personas ${ }^{3}$. De ahí la posibilidad de que haya «iglesias» o reuniones en plural, presentes tanto en una misma región (Gál 1,2) como en una misma ciudad (Rom 16, 5.15). La carta deuteropaulina a los Efesios comienza a emplear el término como un singular colectivo: diciendo que «Cristo amó a la iglesia y se entregó por ella» $(\mathrm{Ef} 5,25)$ quiere decir que amó no sólo a una iglesia y ni siquiera a las iglesias individuales consideradas por separado, sino a toda la societas de los cristianos dondequiera que vivan. Sólo después de la segunda generación cristiana se especifica el término «iglesia» con el adjetivo katholikē, «católica» ${ }^{4}$ en el sentido etimológico de su universalidad. En algunos casos se trataba de comunidades estructuradas, aunque en las primeras décadas las funciones ministeriales se diversificaron según las distintas iglesias y su desarrollo cronológico.

Sin embargo, es importante no imponer esquemas hermenéuticos de sensibilidades recientes a la documentación que tenemos. Por ejemplo, el esquema weberiano de un paso progresivo desde un estadio primitivo de impronta entusiasta sin orden a una fase sucesiva de institucionalización rígida corre el riesgo de apartarnos de la comprensión adecuada de una situación histórica muy compleja. De hecho, la presunta oposición entre carisma e institución es totalmente moderna y tiende a simplificar en exceso los datos disponibles 5 .

1. Aristóteles, Política A2, 1252b, 27-1253a, 29.

2. Ph. A. Harland, Associations, Synagogues, and Congregations. Claiming a Place in Ancient Mediterranean Society, Minneapolis 2003.

3. Sus reuniones se celebran esencialmente en domicilios particulares, donde el entorno más cómodo es el triclinio con capacidad para 30 o 50 personas como máximo. H.-J. Klauck, Hausgemeinde und Hauskirche im frühen Christentum, Stuttgart 1981; R.W. Gehring, Hausgemeinde und Mission. Die Bedeutung antiker Häuser und Hausgemeinschaften - von Jesus bis Paulus, Giessen 2000.

4. Así aparece por primera vez en Ignacio de Antioquía, Esmirn. 8, 2.

5. Además de M. Weber, Wirtschaft und Gesellschaft, Tübingen 1980, véase: C. Fusco (ed.), Carisma e istituzione in movimenti e comunità ecclesiali, Città del Vaticano 2018. 
Es cierto que hay una evolución desde las cartas auténticas de Pablo hasta las Cartas Pastorales pseudoepigráficas (véase más abajo). Pero esto sólo expresa una adaptación a la realidad de las nuevas situaciones ${ }^{6}$.

En todo caso, cualquier discurso sobre la articulación de la comunidad cristiana debe partir del Jesús terreno y de la configuración de sus primeros discípulos, porque después de la Pascua las cosas cambian considerablemente. Distingamos, pues, los dos momentos.

\section{EN LA VIDA TERRENA DE JESÚS}

No es fácil llegar a conclusiones inequívocas sobre la fase del Jesús terreno, pues los relatos evangélicos difieren entre sí, no sólo a la hora de delinear su figura ${ }^{7}$, sino también de perfilar un posible rol emergente entre sus discípulos $^{8}$. La pregunta básica es: ¿qué estructura dio realmente Jesús al grupo de sus discípulos? Estaríamos tentados de responder: ¡ninguno! Ciertamente, ninguno que recuerde ni remotamente la estructura jerárquica de la comunidad contemporánea de Qumrán9. Sin embargo, conviene distinguir.

Por un lado, no parece que Jesús encomendara al grupo de sus discípulos una función pastoral jerárquica. Por otra parte, está muy claro que eligió a un pequeño número de 12 discípulos que se distinguían del resto. Forman un grupo que, al no renovarse tras su muerte (salvo la única sustitución de Judas Iscariote), permanece autónomo, ya que pertenece al pasado, como expresión de un gesto único realizado por el Jesús terrenal. Pues bien, queda suficientemente claro que estos Doce, individual y colegiadamente considerados, no reciben de él ninguna responsabilidad pastoral hacia los demás discípulos. Más bien, se configuran según una triple característica, que podemos definir sucesivamente: israelita, misionera y escatológica.

En primer lugar, los Doce, ya por el simbolismo de su número, representan algo nuevo dentro del pueblo de Israel. De hecho, en el imaginario colectivo judío, el número 12 no recuerda ni a los 12 dioses clásicos del Olimpo ni a

6. Ch. Perrot, Après Jésus. Le ministère chez les premiers chrétiens, Paris 2000, 73-78.

7. Por ejemplo, E. Richard, Jesus: One and Many. The Christological Concept of New Testament Authors, Wilmington 1988, 99-234.

8. Véase S. Guijarro, Jesús y los primeros discípulos, Estella 2007; El camino del discípulo, Salamanca 2015; Fidelidades en conflicto, Salamanca 1998; J. Schlosser, Il gruppo dei Dodici. Ritorno alle origini, Cinisello Balsamo 2013; M. Adinolfi, L'apostolato dei Dodici nella vita di Gesù, Cinisello Balsamo 1985.

9. En ella había una regla precisa para la reunión de la asamblea: «Cada uno según su rango: los sacerdotes se sentarán en primer lugar, los ancianos en segundo lugar, y el resto de todo el pueblo se sentará cada uno según su rango» (1QS 6, 8-9). 
las 12 constelaciones del zodiaco. Se refieren, en cambio, nada más y nada menos que a los 12 patriarcas con los que comienza la propia historia de Israel y, por tanto, a las 12 tribus que constituyen el pueblo elegido. La originalidad de su elección por parte de Jesús se mide por el hecho de que nadie en Israel había elegido nunca un número tan bien delimitado de discípulos con un evidente significado simbólico: ni los antiguos profetas bíblicos, ni los profetas apocalípticos de la época de Jesús, ni ninguno de los rabinos posteriores lo hicieron. La única comparación posible se encuentra en Qumrán, donde aparece un consejo comunitario de 12 laicos y tres sacerdotes bajo la dirección de un Supervisor (1QS 8,1; 1QM 2, 1-2; CD 13-14), pero la dimensión sectaria y sacerdotal de aquella comunidad no coincide con la de Jesús ${ }^{10}$. El número alude, pues, con suficiente claridad a la intención de Jesús de renovar a Israel, casi comenzando de nuevo su historia, como si fueran los nuevos patriarcas espirituales del pueblo de Dios ${ }^{11}$.

En segundo lugar, y este es el dato más evidente, Jesús confía a los Doce una función evangelizadora, aunque limitada al pueblo de Israe ${ }^{12}$. Según los evangelios sinópticos, cuando Jesús los elige lo hace no sólo con el objetivo de que compartan una intimidad particular con él, sino sobre todo «para enviarlos a predicar y para que tengan poder de expulsar demonios» (Mc 3, 1415). El propio evangelista subraya más ampliamente este propósito, cuando narra que Jesús los envía realmente en misión dándoles unas instrucciones concretas (Mc 6, 7-13), que Mateo desarrollará mucho más (Mt 10, 1-42). Por su parte, Lucas repite este envío (Lc 9, 1-6), pero complementa su número con el de otros 70 (o 72) discípulos también enviados con un encargo similar de predicar (Lc 10,1-12). Se puede discutir tanto el número real de este otro grupo como su simbolismo ${ }^{13}$. En cualquier caso, ni a los Doce ni a los Setenta y

10. F. Garcia Martinez, J. Trebolle Barrera, Los hombres de Qumrán, Madrid 1993, espec. 69-71; K. H. Schelkle, La Comunità di Qumran e la Chiesa del Nuovo Testamento, Roma 1970, 76-96.

11. En tiempos de Jesús, «el pubelo de Dios tiene entonces ya una historia que rebasa los mil años. Por consiguiente no puede ser fundado ni instituído» (G. Lohfink, La iglesia que Jesús quería. Dimensión comunitaria de la fe cristiana, Bilbao $\left.{ }^{3} 1998,81\right)$.

12. Así es según Mt 10,5, mientras que el propio evangelista en la conclusión de su escrito pone en boca del Resucitado la idea de una misión de alcance universal $(28,19 \mathrm{~s})$. Sin embargo, el hecho de que durante la vida terrenal de Jesús su predicación no fuera más allá de las fronteras de Israel se desprende tanto de los otros Evangelios como del hecho de que el propio Jesús nunca llevó a cabo una misión más allá de ellas (R. Penna, «Gesù Cristo Salvatore: cristologia e sue implicanze missiologiche», in G. Colzani, P. Giglioni, S. Karotemprel (eds.), Cristologia e Missione oggi, Roma 2001, 364-372).

13. Su simbolismo deriva probablemente del número de los pueblos del mundo presentes en la llamada tabla de las naciones de Gn 10, que según el texto hebreo son 70, mientras 
dos se les encomienda la tarea de un ejercicio pastoral dentro del movimiento de Jesús o de la comunidad de sus discípulos durante su vida.

En tercer lugar, los Doce se sitúan también en un contexto escatológico. La fuente Q nos transmite el siguiente dicho de Jesús: «Cuando el Hijo del Hombre se siente en el trono de su gloria, vosotros también os sentaréis en doce tronos para juzgar a las doce tribus de Israel» (Mt 19, 28 / Lc 22, 30). La apocalíptica contemporánea conocía el tema de la participación en el juicio final de un grupo de personas designadas de diversas maneras: los justos, el pueblo, los santos del Altísimo, los elegidos ${ }^{14}$. Sin embargo, en el dicho de Jesús el acento se pone menos en su función judicial que en su participación en la gloria escatológica de Jesús (en parte porque en el texto paralelo de Lucas no se habla del juicio del Hijo del Hombre, sino de sentarse a comer y beber con él). Sin embargo, la dimensión escatológica de los Doce se encontrará de nuevo en el Apocalipsis de Juan, donde leemos que la futura Jerusalén celestial se apoyará en doce columnas, «en las que están escritos los doce nombres de los apóstoles del Cordero» (Ap 21, 14).

Entre los Doce surge la figura de un discípulo especial, cuyo nombre original en hebreo era «Simeón» (conservado en Hechos 15, 14: 2 Pe 1, 1), pero que se conoce sobre todo por el nombre griego de «Simón» ${ }^{15}$. Jesús le confió un ministerio particular, que en los textos se expresa en tres formas y momentos diferentes según otros tantos evangelistas. En Jn 21, 15-17 es Jesús resucitado quien le dice explícitamente tres veces: «Apacienta mis corderos, mis ovejas». Lucas, en cambio, nos sitúa en el contexto de la última cena, y en la inminencia de la negación, cuando Jesús le dice: «Simón, Simón, ... he rogado por ti para que tu fe no desfallezca; y tú, una vez convertido, fortalece a tus hermanos» (Lc 22, 31-32). Además, encontramos el texto exclusivo de Mateo, según el cual, después de que Simón haya confesado a Jesús como «el Cristo, el Hijo de Dios vivo», Jesús se dirige a él en estos términos: «... Tú

que según la versión griega son 72. Probablemente habría que excluir cualquier referencia a los 70 ancianos elegidos por Moisés en el desierto durante el éxodo (Nm 11, 16-30), ya que, a diferencia de ellos, el grupo de Lucas no tiene ninguna función de gobierno (para Jesús no tiene sentido lo que leemos en Nm 11, 14: «No puedo llevar yo solo el peso de todo este pueblo»). Es posible, por tanto, que el número lucano aluda a una dimensión universal de la misión encomendada por Jesús, aunque sea como proyección retrospectiva de la iglesia lucana, que es misionera.

14. Véase, por ejemplo, lo que se lee en un manuscrito de Qumràn: «Dios no destruirá a su pueblo a través de las naciones; al contrario, Dios juzgará a todas las naciones a través de sus elegidos» (1QpHab 5,3-4).

15. Vease R. E. Brown, K. P. Donfried, J. Reumann (eds.), Pedro en el Nuevo Testamento, Santander 1976; R. Aguirre Monasterio (ed.), Pedro en la Iglesia primitiva, Estella 1991; Ph. Perkins, Peter, Apostle for the Whole Church, Edinburgh 2000. 
eres Pedro, y sobre esta piedra edificaré mi Iglesia, y los poderes del Hades no prevalecerán sobre ella. Te daré las llaves del reino de los cielos: todo lo que ates en la tierra quedará atado en el cielo, y todo lo que desates en la tierra quedará desatado en el cielo» (Mt 16, 18-19).

Aquí se describe la función de Cefas con la antigua metáfora de las llaves que abren y cierran (Is 22, 22, referido a un ministro del rey de Jerusalén: «Pondré sobre su hombro la llave de la casa de David: si él abre nadie cerrará, si cierra nadie podrá abrir»). Sin embargo, es difícil establecer el alcance exacto de este poder, sobre todo porque la función de «atar y desatar» se atribuye a todos los discípulos en Mt 18,18. Pero si también se atribuye separadamente a Pedro y si se habla del poder de las llaves sólo en su caso, su figura no puede homologarse a la de los demás discípulos: por tanto, al menos la iglesia de Mateo reconocía en él un responsable eclesial de tipo particular ${ }^{16}$. En el judaísmo, los verbos «atar y desatar» son propios de la actividad escribal de los rabinos para indicar su función de autoridad en la interpretación de las Escrituras, tanto en un sentido doctrinal para la enseñanza como en un sentido disciplinario para las normas de vida ${ }^{17}$. Pero se entiende que la iglesia de la que se habla es propiedad personal de Jesucristo según la formulación mateana «mi iglesia». Al fin y al cabo, la piedra o roca a la que acudir para saciar nuestra sed, como para los judíos en el desierto, es sólo Cristo (1 Cor 10, 4).

El Cuarto Evangelio, en cambio, describe por separado la figura de un discípulo amado (Jn 13, 23; 19, 26; 20, 2; 21, 7.20) sin nombre, que tiene ciertamente un valor ejemplar, como tipo del discípulo perfecto. De hecho, incluso parece que el evangelista sugiere un antagonismo entre él y Pedro a favor del primero. En efecto, sólo él intima con Jesús en el momento de la Última Cena (13, 23-25); luego le sigue, sólo él, hasta el pie de la cruz, donde recibe a la madre de Jesús como a su propia madre (19, 25-27); además, el día de Pascua, aunque acompañado por Pedro en la carrera hacia el sepulcro de Jesús, sólo de él se dice que, habiendo llegado primero al sepulcro, «vio y creyó» $(20,8)$; finalmente, es él quien revela a Pedro la identidad de Je-

16. De hecho, resulta sorprendente constatar que el Evangelio de Marcos, que de acuerdo con la tradición fue compuesto en Roma siguiendo la figura del propio Pedro (Ireneo, $A d v$. Haer. III, 1, 1; Eusebio, Hist. Eccl. II, 15), ignora por completo la promesa que, según Mt 16, le hizo Jesús.

17. Así lo encontramos en el historiador Flavio Josefo, (Bell 1, 111) y en los textos rabínicos de la Mishna (Terumôt 5, 4; Pesahîm 4, 5). Cabría, por tanto, preguntarse si es filológicamente correcto definir a Pedro no tanto como modelo de discípulo sino como el «supremo rabino de la iglesia» (R. Hummel, Die Auseinandersetzung zwischen Kirche und Judentum im Matthäusevangelium, München $\left.{ }^{2} 1966,63\right)$. 
sús en el lago Tiberíades $(21,7)$. Esta figura, independientemente de cómo se resuelva la cuestión de su identificación histórica, tiene una particular profundidad simbólica y, entre líneas, el evangelista invita a sus lectores a identificarse con él siguiendo el mismo itinerario, que no es sólo de fe, sino también y sobre todo de comunión con Jesús. Por consiguiente, en ese discípulo están todos los demás que vendrían después de él ${ }^{18}$.

\section{EN LAS IGLESIAS POSTPASCUALES}

Partiendo de la base de que el Jesús histórico no utilizó la palabra ekklēsía ${ }^{19}$, hay que señalar que en la etapa inicial del movimiento cristiano es habitual el uso del plural iglesias, en lugar del singular iglesia (véase más arriba), al que nos tiene acostumbrados un lenguaje más teológico que histórico. En ellas, los ministerios adquieren diferentes configuraciones, según los diversos escenarios geoeclesiales en los que se expresan y según sus ulteriores fases de desarrollo. «Hasta aproximadamente el comienzo del segundo siglo, la historia de los ministerios se entremezcla con cambios de roles, amalgamas continuas y mutaciones semánticas, de modo que hay títulos ministeriales que desaparecen y luego reaparecen con nuevos significados. El sentido que hoy damos a palabras como apóstoles, profetas, doctores o presbíteros es singularmente distinto del que tenían esos términos en aquella época» ${ }^{20}$.

El tratamiento de este tema concierne esencialmente a las comunidades paulinas y hay que precisar qué tipo de lenguaje utilizan dichas cartas ${ }^{21}$. Ciertamente, es fácil ver que los ministerios están todos bajo la etiqueta de «carismas»/charísmata (literalmente «favores concedidos») y que está au-

18. R. E. Brown, La comunidad del discípulo amado, Salamanca 1987; J. H. Charlesworth, The Beloved Disciple, Valley Forge PA 1995.

19. De hecho, en los cuatro evangelios sólo se encuentra en Mt 16,18; 18,17 donde se puede explicar sustancialmente a nivel redaccional (U. Luz, El evangelio según Mateo, II, Salamanca 1990, 596).

20. Ch. Perrot, Après Jésus, 140. R. Penna, «Anonimia e pseudepigrafia nel Nuovo Testamento. Comparativismo e ragioni di una prassi letteraria», in Id., Vangelo e inculturazione, Cinisello Balsamo 2001, 795-816. Sobre el tema en general, con amplia bibliografía: E. Cattaneo (ed.), I ministeri nella chiesa antica, Milano 1997.

21. La palabra «carisma» se encuentra en el Nuevo Testamento 17 veces, 16 de ellas en las cartas paulinas; la palabra «diaconía», que aparece 33 veces, se encuentra en Pablo 23 veces (más Heb 1, 14; Ap 2, 19). A este respecto, véase: A. Vanhoye, I carismi nel Nuovo Testamento, Roma 2011; G. Hasenhüttl, Carisma, principio fondamentale per l'ordinamento della chiesa, Bologna 1973; A. D. Clarke, A Pauline Theology of Church Leadership, London-New York 2008; G. Bellia e D. Garribba (eds.), Carismi, diaconia e ministeri dal I al II secolo d.C., «Ricerche Storico-Bibliche»XXV/2, Bologna 2013. 
sente una presunta oposición entre Espíritu e institución ${ }^{22}$. Por ejemplo, en la Primera Carta a los Corintios leemos: «Hay diferentes carismas/dones/charísmata, pero uno solo es el Espíritu; hay diferentes ministerios/servicios/ diakoníai, pero uno solo es el Señor; hay diferentes iniciativas/actividades/ energèmata, pero uno solo es Dios, que obra todo en todos. A cada uno/ ekástōi se le concede una manifestación particular del Espíritu para el bien común»; y se enumeran: el lenguaje de sabiduría, el lenguaje de conocimiento, el don de curaciones, el poder de los milagros, el don de profecía, el don de discernimiento de espíritus, la variedad de lenguas, la interpretación de lenguas (1 Cor 12, 4-10). Como se ve, no hay distinción entre «carismas, servicios, actividades»; a lo sumo, se quiere decir que la pasividad de los carismas, en la medida en que han sido dados, se orienta hacia el dinamismo de los servicios y de las tareas, de modo que éstos no tienen otra raíz que una gracia del Espíritu. El Apóstol, en sus iglesias, tiene incluso el problema del exceso de funciones comunitarias, hasta el punto de que «cada uno» tiene una tarea que realizar, y Pablo no pretende en absoluto sofocar, sino sólo regular las diversas tareas comunitarias. De hecho, considera la necesidad de un «discernimiento de espíritus» (1 Cor 12, 10), asumiendo que no todas las manifestaciones pneumáticas deberían tener una función en la edificación de la iglesia ${ }^{23}$.

Con todo, no deja de sorprender que para ninguno de los ministerios de las iglesias pospascuales se documente un vínculo con el Jesús terrenal, ni para los maestros (incluso negado en $\mathrm{Mt} 23,8 \mathrm{y}$, en cambio, atestiguado en 1Cor 12, 28; Ef 4, 11; 2Tim 1, 11), ni menos aún para los diáconos-presbíteros-obispos. Por el contrario, se atribuyen paradójicamente, no al Jesús histórico, sino a Jesús resucitado en Ef 4, 7-12; aquí, después de haber dicho que «subió por encima de todos los cielos», se afirma que «concedió a unos ser apóstoles, a otros ser profetas, a otros ser evangelistas, a otros ser pastores y maestros, para preparar a los hermanos para el ministerio». No en vano, un poco antes, al hablar de la iglesia como mancomunidad de

22. El vínculo semántico entre cháris y chárisma está bien expresado en un bello pasaje de Filón Alejandrino: «Todo es gracia (cháris) de Dios y nada es un favor (chárisma) de la creación, ya que la creación no posee nada, sino que todo es propiedad de Dios; por eso la gracia (cháris) sólo le pertenece a él como característica propia. Así pues, a los que buscan el fundamento de la creación habría que responderles que es la bondad (agathótēs) y la gracia (cháris) de Dios, las cuales el ha regalado (echárisato) a la humanidad; pues todo lo que hay en el mundo y el mundo mismo es un regalo (dōreá), un beneficio (euergesía) y un favor (chárisma) de Dios» (Spec. Leg. 3, 78).

23. A. Munzinger, Discerning the Spirits. Theological and Ethical Hermeneutics in Paul, Cambridge 2007. 
judíos y gentiles, el autor ha hablado de Cristo que «creó de los dos en sí mismo un solo hombre nuevo» a través de la cruz (Ef 2, 15-16); al margen de la metáfora antropológica, éste es el único caso en el NT en el que Cristo Jesús es presentado, no como mediador de la creación primordial, sino como autor en primera persona de una creación que es toda suya: como diría San Agustín, moriente Christo ecclesia facta est (Enarr. in Ps. 127, 11). No en vano Pablo habla en otro lugar de Cristo, no como fundador de la Iglesia en el pasado, sino como su actual y perenne «fundamento» (1Cor 3, 10-11). Por lo demás, la lista de ministerios que aparece en Ef 4, 11 no coincide con las que se encuentra en otras iglesias y en las cartas dirigidas a ellas (Rom 12, 5-8; 1 Cor 12, 4-11.28-30).

Por consiguiente, conviene distinguir los diversos tipos de ministerios, al menos en lo que se refiere a las diferencias entre las iglesias judeocristianas y las paulinas, a las que hay que añadir también las iglesias joánicas ${ }^{24}$.

- Las iglesias judeocristianas son las de la primera hora, que encontramos establecidas en Palestina, especialmente en Jerusalén, pero también en otros lugares (Galilea y ciudades de la llanura costera). También Antioquía de Siria y, en general, la zona siria deben incluirse en esta tipología al igual que Damasco, aunque sepamos muy poco de ella. Las iglesias de la segunda y tercera generación también pertenecen a la misma tipología, al igual que la iglesia de Roma, anterior a Pablo, así como aquellas que se perciben detrás de las Epístolas Pastorales (pseudoepigráficas).

En la iglesia de Jerusalén, según los Hechos de los Apóstoles, se impuso una distinción jerárquica, señalada de diversas maneras: primero se habla sólo de «apóstoles» o de «Pedro y los demás apóstoles» (hasta el capítulo 11) ${ }^{25}$; luego se habla de «apóstoles y presbíteros» (capítulos 15-16), que parecen tener como paralelo la distinción judía entre «jefes del pueblo y ancianos» $(4,5.8 .23 ; 25,15)$; finalmente sólo encontramos a «los presbíteros junto con Santiago» $(21,18)$, sabiendo que este último no es uno de los Doce, sino un pariente cercano de Jesús atestiguado diversamente en las fuentes con un papel de primer orden en los orígenes del cristianismo ${ }^{26}$. Evidente-

24. Véase: R. Aguirre (ed.), Así empezó el cristianismo, Estella 2011, 139-340; R. Penna, Le prime comunità cristiane. Persone, tempi, luoghi, forme, credenze, Roma ${ }^{2} 2017,61-223$.

25. La elección de los «siete» (Hch 6) no representa una verdadera jerarquía de ministerios, ya que, al menos al principio, son meros sirvientes de las mesas; más tarde, sin embargo, también se insinúa explícitamente un ministerio de predicación, al menos en lo que respecta a Felipe (8, 5.35 y $21,8-9)$.

26. Incluso el historiador judío Flavio Josefo habla de él con respeto (Ant. Jud. 20, 200201: relata su lapidación en el año 62), mientras que el historiador cristiano del siglo IV 
mente, hubo un cambio estructural, sin duda debido a la desaparición de los Doce, pero también a la prevalencia de una organización con una aparente impronta judaica, integrada por un responsable individual asistido por un colegio de ancianos; incluso la carta de Santiago atestigua la presencia de los presbiterios como grupo institucionalizado (Sant 5,14). Sin embargo, la iglesia de Jerusalén conoce también la figura carismática de los profetas, que, repitiendo quizá el tipo de los profetas del Antiguo Testamento, hablan libremente por inspiración del Espíritu y pueden pasar de una iglesia a otra (Hech 11, 27; 15, 32; 21, 9-10) $)^{27}$.

Para la zona de Siria tenemos el testimonio más bien arcaico de la Didajé, un importante escrito del que se desprende una imagen de la iglesia que atribuye a los profetas la función predominante de guías espirituales, mientras que los obispos y los diáconos (los presbíteros están ausentes) son elegidos para dirigir la comunidad ${ }^{28}$. Poco después, el apócrifo cristiano anónimo Ascensión de Isaías, originario de esta misma región y compuesto entre los últimos años del siglo I y los primeros del siglo II, atestigua una controversia a favor de un grupo de profetas cristianos, combatidos y puestos a la defensiva por las autoridades eclesiásticas locales, probablemente pertenecientes a una estructura presbiteral, entre los que algunos ejercen funciones episcopales (en plural) ${ }^{29}$. Las cartas posteriores de Ignacio, obispo de Antioquía, en torno al año 110 (¿o de una redacción posterior?) insistirán en este momento en la función central del obispo como figura única, en singular, al frente de la comunidad cristiana.

Las iglesias a las que se dirigen las cartas pastorales «paulinas», situadas en Éfeso y Creta, presentan una situación diferente. Por un lado, se estructuran ministerialmente según una nueva gradación que incluye «obispos, presbíteros y diáconos» (1 Tm 3, 1-7.8-13; 5, 17-25), aunque los obispos no son

Eusebio de Cesarea lo menciona (¡y no a Pedro!) como el primer obispo de Jerusalén (Hist. Eccl. 2, 23, 1). A él se le atribuye la carta canónica que lleva su nombre, caracterizada por posiciones casi antipaulinas. En una composición judeocristiana posterior del siglo III, titulada Homilías Pseudoclementinas, leemos incluso que Pedro exhorta a los presbíteros a «huir de todo apóstol, doctor o profeta, que no haya sometido antes cuidadosamente su predicación a Santiago, llamado hermano de mi Señor» $(11,35,1)$. C. Gianotto, Ebrei credenti in Gesù, Milano 2012, 56-73.

27. Sobre los profetas cristianos, véase: Ch. Perrot, Après Jésus, 215-228; véase también: D. E. Aune, La profezia nel primo cristianesimo e il mondo mediterraneo antico, Brescia 1996, espec. 350-613.

28. G. Visonà, Didachè, insegnamento degli apostoli, Milano 2000, 212-213.

29. Véase AscIs 3, 13-4,22: «Amarán los oficios aunque estén vacíos de sabiduría ... cambiarán sus vestidos por los de los amantes del oro ... y harán vana la profecía de los profetas» (E. Norelli, Ascensio Isaiae, II - Commentarius, Turnhout 1995, 162-284). 
más que miembros del grupo de los presbíteros ${ }^{30}$. Se les dan instrucciones específicas tanto de tipo moral, sobre sus virtudes personales, como institucionales sobre la tarea que deben realizar. Por otra parte, en estas iglesias desaparece la figura del profeta, mientras que la preocupación por la sana doctrina toma el relevo para hacer frente a la aparición de falsos maestros (no en vano el término «hereje» aparece aquí por primera vez en el lenguaje cristiano, en Tito 3, 10) ${ }^{31}$. El pastor sólo debe «guardar el depósito» de la fe (1 Tm 6, 20; 2 Tm 1, 14): expresión que indica una situación reciente respecto a un pasado apostólico ya algo lejano del que procede una especie de legado que debe conservarse intacto, para lo cual los pastores tienen la tarea de amonestar, exhortar y reprender.

Por su parte, la iglesia de Roma tiene sus propias características ${ }^{32}$. Aunque conoce una interpretación del evangelio de sabor judeocristiano, ofrece una estructura ministerial original: a mediados de los años 50, la carta de Pablo a los romanos menciona sólo una figura algo difuminada de «presidente» (ho proistámenos), que se enumera dentro de una lista de otros ministerios enunciados con una terminología no técnica («el que enseña, el que exhorta, el que comparte, el que preside, el que hace obras de misericordia»: Rom $12,7-8)$ y debe entenderse no en singular como una figura única para toda la iglesia de Roma, sino en un sentido distributivo en relación a los diversos individuos responsables de cada una de las comunidades cristianas (al menos tres) de la capital. En este sentido debe entenderse también el plural «los jefes»/hēgoúmenoi mencionado en la Epístola a los Hebreos $(13,7.17)$ que con toda probabilidad fue enviada a la iglesia de Roma después del año 70. Por su parte, la llamada carta de «Clemente» a los Corintios (mediados de los años 90) desconoce aún la figura de un individuo responsable de toda la comunidad, ya que lleva como remitente no el nombre individual de Clemente (que se añadió un siglo más tarde) sino sólo colectivamente «la iglesia de Roma». Así será de nuevo hacia el año 110 (ya que la carta de Ignacio a los romanos se dirige «a la iglesia amada... que preside en la capital del territorio romano») y hacia el 140 (cuando el escrito de Hermas titulado El pastor ha-

30. De hecho, según el libro de los Hechos, en Mileto Pablo manda llamar a «los presbíteros» de la iglesia de Éfeso y les dice que el Espíritu Santo los ha puesto «como obispos» para pastorear la iglesia de Dios $(20,28)$.

31. El título de «profeta» se reserva curiosamente para un poeta cretense y pagano (Tit 1, 12: tal vez Epiménides), y, aunque se registra la intervención de profetas en la elección de Timoteo (1 Tim 1,18; 4,14), es ahora el léxico de la enseñanza el que tiene mayor protagonismo ( 5 veces didáskein, 2 veces didaché, 3 veces didáskalos, 15 veces didaskalía).

32. Sobre la configuración judeocristiana de la iglesia de Roma en el siglo I, véase R. Penna, Carta a los Romanos. Introducción, versión y comentario, Estella 2013, 24-43. 
bla de nuevo en plural de «los jefes de la iglesia», «los presbíteros que están a la cabeza de la iglesia» y de los «obispos», de nuevo sólo en plural) ${ }^{33}$. Esta situación se conjuga de manera interesante, ya en los años 90 del siglo I, con la nueva idea de una sucesión apostólica, atestiguada por primera vez por la llamada carta de Clemente, que sin embargo habla de esta en plural ${ }^{34}$.

-Las iglesias paulinas, fundadas por san Pablo, abarcan la amplia zona geográfica que va desde el centro de la península de Anatolia hasta toda Grecia (Galacia, Asia [Éfeso y Colosas], Macedonia [Filipos y Tesalónica], Acaya [Atenas y sobre todo Corinto]) y presentan una tipología ministerial diferente. En general, puede decirse que están menos institucionalizadas que las judeocristianas $^{35}$. Ciertamente, en este caso se podría hablar, más que nunca, de una verdadera «primacía» ejercida por el propio Pablo como su fundador y pastor, que declara su «preocupación por todas las iglesias» (2 Cor 11, 28). Sin embargo, no tiene un representante personal o un vicario en cada una de ellas ${ }^{36}$. Más bien, existe el problema de una sobreabundancia, casi una anarquía ministerial, que el Apóstol no pretende sofocar en absoluto, sino sólo explicar y en parte organizar. Un dato seguro es que en estas iglesias no existe la figura del presbítero, mientras que la del obispo apenas se menciona de pasada sólo para la iglesia de Filipos, pero en plural (en Flp 1, 1). A decir verdad, Pablo no cuenta aún con una terminología fija para designar los ministerios, como se desprende de la lista que figura en la Primera Carta a los Corintios:

A algunos Dios los ha colocado en la iglesia en primer lugar como apóstoles, después como profetas, luego como maestros. Después vienen los milagros, los dones de curar, de cuidar, de gobernar, de hablar en lenguas. ¿Acaso son todos son apóstoles? ¿Son todos profetas? ¿Son todos maestros? ¿Hacen todos milagros? ¿Poseen todos el don de la curación? ¿Hablan todos en lenguas? ¿Acaso todos las interpretan? (12, 28-30).

33. Hermas, El pastor, Visiones 2, 2, 6; 2, 4, 2; Parábolas 9, 27, 2.

34. «Nuestros apóstoles ... constituyeron [obispos y diáconos], y también dieron órdenes de que, cuando muriesen, otros hombres probados se hiciesen cargo de su ministerio» (Clemente 44, 1-2).

35. Resulta sintomático, por ejemplo, que el historiador del siglo IV Eusebio de Cesarea consigne las sucesiones episcopales continuas de las iglesias de Roma, Alejandría, Antioquía y Jerusalén, sustancialmente todas de origen judeocristiano, pero no consigne ninguna de las iglesias paulinas: sólo de Corinto menciona como primer obispo a un tal «Primo» pero sólo a finales del siglo I, saltando luego a la segunda mitad del siglo II con Dionisio (Hist. Eccl. 4, 22-23).

36. Lo que leemos en Hechos 14, 23 («Establecieron allí, en cada comunidad, algunos presbíteros»), aparte de que sólo es válido para las iglesias del primer viaje misionero (Iconio, Listra, Derbe), debe explicarse no tanto en el plano histórico como en el redaccional, pues en sus cartas Pablo no conoce en absoluto la figura del presbítero. 
Entre estos, los ministerios que poseen una terminología estandarizada son ciertamente los primeros, es decir, los apóstoles y los profetas, y sólo hipotéticamente los maestros (1 Cor 12, 28). Pero aquí nos encontramos con una originalidad típicamente paulina, al tiempo que debemos observar una diferencia no marginal entre ellos. Los apóstoles, para San Pablo, son distintos de los Doce (1Cor 15, 5 y 7) y no representan ningún numerus clausus, ya que son simplemente los misioneros, anunciadores del evangelio y fundadores de iglesias (Rom 10, 15: «¿Cómo lo anunciarán, si no han sido enviados [eàn mé apostalôsin]?») tanto que entre ellos también puede haber una mujer (así Junia en Rom 16:7; véase más abajo): son ellos los que ponen a Cristo como fundamento (1 Cor 3, 10-11) y se convierten ellos mismos en fundamento (Ef 2, 20-21). Los profetas, por su parte, no son los itinerantes del tipo judeocristiano (como en Mt 7, 15), sino miembros estables de las comunidades, transmisores de las revelaciones recibidas del Espíritu Santo, entre los que también puede haber mujeres (1Cor 11, 5). A estos últimos, según Pablo, hay que darles necesariamente espacio en las comunidades, y si alguna vez plantean algún problema es sólo cuestión de discernir en cuál de ellos está realmente presente el Espíritu (1 Tes 5, 19-21; 1 Cor 12, 10). En cuanto a los maestros (didáskaloi), tienen la tarea de instruir a la comunidad con una enseñanza más continuada, quizá utilizando las Escrituras; se enumeran en tercer lugar en el pasaje citado de 1 Cor 12, 28, pero es un caso único en las cartas auténticas de Pablo, ya que en otros lugares se habla genéricamente de «el que enseña» junto a otros ministerios no institucionales $(\text { Rom 12, 7) })^{37}$.

En las iglesias paulinas se da una prioridad absoluta a la palabra evangélica: es la palabra del evangelio. Ella funda la iglesia y sobre ella esta se apoya (1 Tes 2, 13; 1 Cor 1, 17; Gal 3, 2.5; Rom 10, 17); además, en torno a ella giran los distintos ministerios. De hecho, en la lista de 1Cor 12, 8-10 (la sabiduría, la ciencia, la fe que obra milagros, la capacidad de sanar, el poder de los milagros, la profecía, el discernimiento de espíritus y la glosolalia o hablar de forma ininteligible) aparecen en primer lugar dos carismas que deberían fundamentar el anuncio cristiano. Por otra parte, la preeminencia de la palabra no debe implicar ninguna preferencia para quien es su ministro, pues no es más que su servidor ( 1 Cor 3, 5; 4, 1; 2 Cor 1, 23; 3, 6; 4, 5). Además, observamos que las funciones de gobierno se consideran secundarias, ya

37. Además, la tríada nunca aparece tan claramente como en 1 Cor 12, 28, ya que en otros textos, posteriores a Pablo, sólo se menciona a los «profetas y maestros» (en Antioquía: Hch 13, 1) o a los «apóstoles y profetas» $(\mathrm{Ef} 2,20)$ o, de nuevo, a los «apóstoles, profetas, evangelizadores, pastores y maestros» (Ib. 4, 11). 
que en la lista de 1Cor 12: 28 las kybernéseis / «direcciones o gobiernos», es decir, las personas que ejercen un cargo de liderazgo, aparecen en penúltimo lugar en una serie de ocho ministerios. En otro lugar, Pablo habla de «presidentes» en plural para una comunidad individual (1 Tes 5, 12: proistámenoi) o más genéricamente aún de aquellos «que se han puesto al servicio de los santos» (1 Cor 16, 15-16).

La preocupación típica del Apóstol con respecto a los ministerios eclesiales es subrayar su unidad de origen, su dimensión comunitaria y, en consecuencia, la armonía que debe reinar entre ellos. Para indicar su origen utiliza incluso una formulación esencialmente trinitaria: «Hay diversidad de carismas, pero un mismo Espíritu; hay diversidad de servicios, pero un mismo Señor; hay diversidad de actividades, pero un solo Dios que obra todo en todos» (1 Cor 12: 4-6). Por lo tanto, antes de la multiplicidad, sólo hay un origen divino, que sin embargo, debido a la distinción entre Espíritu-Señor-Dios ya implica una complejidad y, en cualquier caso, una realidad divina que no es plana. El hecho de que esta formulación no comience con Dios (-Padre: como suele ocurrir), ni con el Señor (Jesucristo: como ocurre en 2 Cor 13, 13), sino con la mención del Espíritu (Santo), significa que en los ministerios vemos actuar a quien por definición es vida, dinamismo, imaginación viva, libertad (2 Cor 3,17$)$, del cual en otro lugar Pablo nos invita incluso a ser «fervorosos» (Rom 12, 11: zéontes).

Los ministerios también tienen una dimensión comunitaria específica, en un doble sentido. Por un lado, no constituyen algo sectorial, como si pertenecieran sólo a alguien: es, en cambio, «a cada uno» a quien el Espíritu distribuye los carismas (1 Cor 12,11); esto significa que son muy polifacéticos (la lista que da Pablo es sólo un ejemplo), de modo que en la iglesia cada uno tiene su parte, que le es propia, independientemente de cómo se manifieste. Por otro lado, deben colaborar al bien común, ya que lo importante es la edificación, la construcción de la comunidad, es decir, su crecimiento ordenado y no descontrolado $(1 \text { Cor } 12,7 ; 14,40)^{38}$. Es precisamente este riesgo de desgarro el que ordena la exhortación al ágape o amor mutuo, y por tanto a la armonía en la iglesia. De hecho, viendo las cosas con perspectiva, uno se da cuenta de lo importante que es una advertencia de este tipo. En efecto, es

38. Pablo ejemplifica este principio en 1 Cor 14 en la comparación entre los dos carismas de la glosolalia (discurso extático, incomprensible, que no transmite ningún logos) y la profecía (comunicación eficaz, sensible, que construye algo); aunque no desprecia el primero, se inclina claramente por el segundo: «En la ekklesia prefiero decir cinco palabras con mi inteligencia para instruir también a otros, que diez mil palabras con el don de lenguas» (1Cor 14, 19). 
sintomático que cada vez que surge el discurso sobre los ministerios, Pablo haga también un discurso sobre el amor: esto ocurre no sólo en la posterior carta a los Efesios (4,11-16), sino también en la carta a los Romanos (12, 6-10) y, sobre todo, en la primera carta a los Corintios. En ella, todo el capítulo decimotercero, incrustado en un discurso sobre los ministerios, contiene un solemne elogio del ágape que se ha convertido en un clásico: «iSi no tuviera amor/caridad, no sería nada...! $!^{39}$

- La visión joánica de la Iglesia también merece una atención especial. Aunque no es fácil situar su realidad geográficamente (tal vez Éfeso y sus alrededores), se basa en la hermosa idea de una comunidad de amigos: «Ya no os llamo siervos, sino amigos... Soy yo quien os he elegido» (Jn 15, 1216). En el mundo antiguo tal idea sólo se encuentra en Epicuro, para el cual la amistad se define y se vive como «el bien más grande, inmortal» ${ }^{40}$. Y el dicho de Jesús, según el cual «nadie tiene mayor amor que el que da la vida por sus amigos» (Jn 15, 13), encuentra su mejor paralelo en la frase del propio Epicuro, según el cual el sabio «morirá incluso, si es necesario, por un amigo» ${ }^{41}$. La articulación de la comunidad joánica tiene su fundamento en la igualdad de sus miembros. La figura del discípulo amado sólo cumple la función histórica de haber sido el testigo privilegiado de Jesús y, por tanto, de ser el garante de la tradición que se remonta a él. Pero todos han recibido igualmente el Espíritu y todos son igualmente instruidos por Dios (Jn 3, 34; $6,45 ; 15,3 ; 1 \mathrm{Jn} 2,20.21 .27)$. El servicio mutuo, expresado icónicamente en el lavatorio de los pies (Jn 13, 6-11), y el amor fraterno como expresión de un nuevo mandamiento (Jn 13, 34-35) representan todo lo que el Evangelio joánico tiene que decir sobre la ministerialidad de la Iglesia. Sólo así se entiende la importancia del velado reproche dirigido en la tercera carta joánica a un tal Diótrefes «que codicia el primer puesto» (3Jn 9).

-Conclusiones. A partir de lo que hemos visto sobre los carismas y las diaconías en las comunidades eclesiales más antiguas, hay que deducir al menos tres conclusiones. Una se refiere a la pluralidad de formas ministeriales que, aun teniendo en cuenta la presencia común de los «apóstoles y profetas», difieren incluso de una iglesia a otra, hasta que surge una estructura más institucionalizada que ordena y reduce las manifestaciones del Espíritu al trío

39. R. Penna, «Solo l'amore non avrà mai fine. Una lettura di 1Cor 13 nella sua pluralità di senso», in Id., L'apostolo Paolo. studi di esegesi e teologia, Cinisello Balsamo 1991, 223-239.

40. Epicuro, Máximas 27.

41. Diogenes Laercio, Vit. Philos. 10, 121b. 
obispo-presbítero-diácono. Una de las razones de esta evolución podría ser la aparición de falsas doctrinas judaizantes o gnósticas que había que controlar ${ }^{42}$.

El segundo resultado se refiere a las funciones ministeriales que claramente desempeñan varias mujeres (especialmente en Rom 16; 1Cor 11), como si se tratara de decir que en Cristo no hay oposiciones de género (Gal 3,28 ). Con ello se abre el capítulo sobre el feminismo de Pablo, que ha despertado un gran interés en los últimos años con una amplia bibliografía ${ }^{43}$. Aunque no pertenecieran al grupo de ancianos/presbíteros, podían profetizar públicamente en la asamblea ${ }^{44}$, algo que en el judaísmo no ocurría. Tanto en los Hechos como en las Cartas se recuerda a un número considerable de mujeres que fueron compañeras de Pablo. Algunas son descritas con el título de ministro (diákonos: Febe en Cencreas, en Rom 16, 1) o colaborador (synergós: Prisca, en Rom 16, 3) o misionero (apóstolos: Junia, en Rom 16, 7), y muchas se dedicaban a los ministerios de enseñanza y predicación (Rom 16, 1.3.7; Fil 4, 2.3: «Evodia y Síntique lucharon conmigo por el evangelio». Aquellas que «se han esforzado» $\mathrm{y}$ «han trabajado» llevaban a cabo actividades específicas para la iglesia (Rom 16,6.12), mientras que otras pertenecían a familias pudientes y apoyaban a Pablo como benefactoras o ponían sus casas a disposición para que fueran iglesias domésticas (Rom 16, 15; Col 4, 15; Flm 1-2; Rom 16, 13, 15-16; Hechos 16, 14-15,40). Es interesante lo que ya en el siglo IV escribía San Juan Crisóstomo, comentando el pasaje de Rom 16, 6 donde se dice de una tal María que «ha trabajado mucho por vosotros»; afirmando sin rodeos: «Una vez más Pablo exalta y señala a una mujer como ejemplo, iy una vez más los hombres nos sentimos abrumados por la vergüenza! O mejor dicho, no sólo nos abruma la vergüenza, sino que también nos honra. Nos sentimos honrados, de hecho, porque tenemos tales mujeres con nosotros; pero nos abruma la vergüenza, porque en comparación con ellas estamos muy por detrás» (PG 60, 668).

42. Ch. Perrot, Après Jésus, 254-258.

43. Véase: A. Vögtle, «Donne e funzioni ecclesiali», in Id., La dinamica degli inizi. Vita e problemi della Chiesa primitiva, Milano 1991, 131-161; P. Grelot, La donna nel Nuovo Testamento, Cinisello Balsamo 1996; J. Okland, Women in their Place. Paul and the Corinthian Discourse of Gender and Sanctuary Space, London-New York 2004; B. W. Winter, Roman Wives, Roman Widows. The Appearance of New Women and the Pauline Communities, Grand Rapids MI / Cambridge UK 2003; E. Prinzivalli, «Donne e ministeri nella chiesa antica: Alcune osservazioni preliminari», Augustinianum 57 (2017) 5-17; R. Penna, «Il femminismo di San Paolo», in: Nuria Calduch-Benages (ed.), San Paolo e le donne, Milano 2019, 95-102.

44. La exhortación de 1Cor 14, 34 a guardar silencio en la asamblea tiene muchas explicaciones (véanse los comentarios), pero se contradice tanto con 1Cor 11, 5 (donde se dice que cualquier mujer en la asamblea puede profetizar) como con Gál 3, 28 (que excluye la diferencia de género). 
La tercera conclusión es que todas estas formas de ministerio son de carácter laico, incluso la tríada presente en las Pastorales. A no ser que se entienda la laicidad como una simple distinción respecto a los que desempeñan funciones públicas específicas, las primeras comunidades cristianas no conocen ministerios de tipo estrictamente sacerdotal, aunque sólo sea porque no tienen templos que gestionar. La definición de todos los cristianos como sacerdotes se encuentra esencialmente en dos escritos: la Primera Carta de Pedro y el Apocalipsis de Juan. A decir verdad, ya Pablo supone algo parecido pues evita utilizar el léxico sagrado-ritual incluso con respecto a Cristo, lo cual implica que no sirve para designar una categoría particular de personas dentro de la iglesia; es más, define a la propia iglesia con la categoría sacral del Templo de Dios (1 Cor 3, 16-17); además, invita a sus destinatarios a ofrecerse como sacrificio diario al Señor, como si se tratara de un acto cultual realizado indistintamente por todos los bautizados (Rom 12, 1). Sin embargo, en los dos escritos citados (1Pe 2, 5.9; Ap 1, 6; 5, 10; 20,6) se dice expresamente que los cristianos son todos juntos «una comunidad sacerdotal santa y regia» y todos individualmente «sacerdotes para nuestro Dios», de modo que pueden «ofrecer sacrificios espirituales agradables a Dios por medio de Jesucristo». En el origen de estas declaraciones hay ciertamente un pasaje del Antiguo Testamento en el que se define a todo el pueblo de Israel como «un reino de sacerdotes y una nación santa» (Ex 19, 6). Esta definición es en realidad sólo metafórica, ya que de hecho en Israel sólo los miembros de la tribu de Leví ejercen el sacerdocio en el Templo ${ }^{45}$. Pero en la comunidad cristiana no hay una categoría de personas que se designe por separado como grupo de sacerdotes; esto sólo ocurrirá a partir del siglo III ${ }^{46}$.

45. Un antiguo midrash rabínico explica: «Antes de que Aarón fuera elegido de forma especial, todos los israelitas estaban cualificados para el sacerdocio; después de que Aarón fue elegido, todos los demás israelitas quedaron excluidos» (Mek. Ex. 12, 1, 51-52).

46. Tertuliano llamará al obispo summus sacerdos (Sobre el bautismo 17), pero también dirá: «¿Acaso los laicos no somos también sacerdotes?» (Exhortación a la castidad 7). Y así, el alejandrino Orígenes escribirá admirablemente: «Sois un pueblo sacerdotal y, por tanto, tenéis acceso al templo. Cada uno de nosotros tiene en sí mismo su propio holocausto y es él quien aviva el fuego en el altar para que siempre haya algo que quemar. Por eso, si renuncio a todo lo que poseo llevando mi cruz y siguiendo a Cristo, ofrezco mi holocausto en el altar de Dios. Si por caridad entrego mi cuerpo a las llamas y si adquiero la gloria del martirio, me ofrezco como holocausto en el altar de Dios. Si amo a mis hermanos hasta dar la vida por ellos, si lucho hasta la muerte por la justicia o por la verdad, ofrezco mi holocausto en el altar de Dios. Si mortifico mis miembros de toda concupiscencia carnal, si el mundo es crucificado por mí y yo por el mundo, ofrezco mi holocausto en el altar del Señor y me convierto en el sacerdote de mi propio sacrificio. Así es como ejerzo mi sacerdocio» (Sobre el Levítico, Homilía 9:9: PL 12:521s). Véase: E. Dal Covolo, «Laici e laicità nei primi secoli della Chiesa», Rassegna di teologia 37 (1996) 359-375. 
En la raíz hay también una certeza típicamente cristiana, que ve en Jesús el único y verdadero Sacerdote de la Nueva Alianza, como explica la Carta a los Hebreos ${ }^{47}$.

Los orígenes cristianos, por lo tanto, no conocen dentro de la iglesia una verdadera división entre sacerdotes y laicos, no sólo porque estos términos simplemente no existen, sino además porque los ministros de la iglesia desempeñan una función de presidencia que no es propiamente sacerdotal, ya que los sacerdotes son todos los bautizados ${ }^{48}$.

\section{COMUNIÓN FRATERNA Y MINISTERIALIDAD}

Es un dato fundamental que la identidad cristiana se basa en una común filiación divina (adoptiva), derivada de la misma fe y del mismo bautismo: «A todos los que le recibieron les dio la posibilidad de ser hijos de Dios» (Jn 1,12 ); «Porque todos vosotros sois hijos de Dios por la fe en Jesucristo» (Gal 3, 26). De ahí el asombro: «Ved qué amor tan grande nos ha tenido el Padre, como para llamarnos hijos de Dios, pues realmente lo somos» (1 Jn 3, 1). La configuración como hijos revela un acceso a Dios que, aunque mediado por Jesucristo, hace posible una relación directa con él. Como hijos, los cristianos no sólo deben postrarse ante Dios, como hacen a veces los perros ante su amo, sino que pueden y deben mirarle confiadamente a los ojos, pues con Cristo son también herederos tanto de las antiguas promesas como del reino de los cielos (Gál 4, 7; Rm 8, 16-17). Pues bien, la Iglesia no es otra cosa que una comunidad de hijos, en la cual hay un solo padre. La igualdad de los discípulos está bien subrayada por una palabra de Jesús en el Evangelio según Mateo: «No os hagáis llamar 'rabino', porque uno es vuestro maestro y todos sois hermanos... Y no os hagáis llamar «guías»/kathēgētaí, porque uno es vuestro guía, Cristo» (Mt 23,8.10). Es posible que la formulación de estas frases esté condicionada por el momento histórico en el que escribe Mateo, hacia finales del siglo I, cuando el judaísmo, tras el desastre del año 70, se organizó en forma de rabinismo, y por ello pueden tener un valor polémico antirrabínico (véanse los siete siguientes «Ay de vosotros, escribas y fariseos hipócritas, que vienen a continuación»). Pero el valor axiomático de la exhortación, incluso en forma de imperativo, permanece. Si Mateo escribe entonces «todos los hermanos» en lugar de «todos los discípulos»,

47. Sobre este tema, véase: R. Penna, Un solo corpo. Laicità e sacerdozio nel cristianesimo delle origini, Roma 2020, 63-91.

48. R. Penna, Un solo corpo, 177-200. 
es porque inmediatamente después Jesús adopta una terminología parental, pues añade: «Y no llaméis a nadie 'padre' en la tierra, porque uno es vuestro padre, el del cielo». Sobre la base de esta igual dignidad, nadie en la Iglesia puede pretender ser más hijo que otro, ni menospreciarse a sí mismo como menos hijo que otro.

Por eso, el calificativo de hermano/adelfós en lugar de discípulo/mathētēs enfatiza sobre todo la relación intracomunitaria de igualdad mutua, que depende más de la regeneración personal que de la enseñanza intelectual, como si dijera que lo que iguala a los discípulos reside en su nueva naturaleza adquirida por el bautismo (Rom 6, 5), y no sólo en una relación extrínseca, por muy igualitaria que sea. La fraternidad que une a los discípulos de Jesús también está marcada por una relación particular con él. Esto se ve bien cuando, con ocasión de una visita que le hacen «su madre y sus hermanos» (Mc 3, 31), él casi reniega de su familia terrenal, como leemos en el relato evangélico: «¿Quién es mi madre y quiénes son mis hermanos? Y mirando a los que estaban sentados alrededor de él, dijo: «¡Estos son mi madre y mis hermanos! El que hace la voluntad de Dios, ése es mi hermano, mi hermana y mi madre» (Mc 3, 33-35).

Con todo, la denominación de adelfós, que se refiere en primer lugar a los cristianos en general, hasta el punto de que, por ejemplo, la Primera Carta de Pedro desconoce el término «iglesia»/ekklēsía, y lo sustituye por adelfótēs/«hermandad, fraternidad» $(1 \mathrm{Pe} 2,17 ; 5,9)^{49}$, también se utiliza para designar a los que ejercen un ministerio (Rom 16, 23; 1 Cor 1, 1; 16, 12; 2 Cor 1,$1 ; 8,18 ; 9,3$; Fil 1, 14; Col 4, 9; 1 Ts 3, 2). El concepto de fraternidad tiene esta connotación cuando se utiliza el término «hermanos» con el artículo, que implica una distinción de la «comunidad/iglesia» (1 Cor 16, 1920: «Aquila y Prisca os saludan junto con la comunidad reunida en su casa. Os saludan todos los hermanos») o se aplica a los creyentes en general (Ef 6, 23-24; Fil 4, 21-22. «Los hermanos que están conmigo te saludan. Todos los santos os saludan»; Col 4, 15) o a los compañeros de misión: «Pablo... y todos los hermanos que están conmigo» (Gal 1, 1-2). En otros casos el término se refiere a colaboradores que aparecen como remitentes en la carta junto con Pablo (1Cor 1, 1: «Pablo y el hermano Sóstenes»; 2Cor 1, 1; Fil 1, 1; Col 1, 1; 1 Tes 1, 1; cf. Hch 13, 1-3). La designación «hermanos» puede referirse

49. Curiosamente, fuera del griego bíblico (incluidos $1 \mathrm{Mac} 12,10.17 ; 4 \mathrm{Mac} 9,23 ; 10$, $3.15 ; 13,19.27$ ), este término sólo se encuentra en el filósofo pagano Dión Crisóstomo (ca. 50-110), Oración 38, 15, donde define «hermandad» como «concordia de hermanos» (adelfôn homónoia). Véase: P. Trebilco, Self-Designations and Group Identity in the New Testament, Cambridge 2012, 16-67. 
tanto a los trabajadores estables de las comunidades locales (Flp 1, 14: «La mayoría de los hermanos en el Señor, animados por mis cadenas, proclaman aún más audazmente la Palabra sin temor»; cf. Col 1, 2 con 4, 15-16; cf. Hech $1,29 ; 12,17)$, así como los que se dedican a una misión itinerante (2 Cor 2, 13; 8, 18.22-23: «Con Tito enviamos también al hermano [¡anónimo!] a quien todas las iglesias alaban por el evangelio»; cf. Hech 10, 23; 11, 12). Pablo conoce, pues, una verdadera fraternidad ministerial, aparte de la que es común a todos sus destinatarios.

\section{CONCLUSIÓN}

Para concluir, habría que preguntarse si no se debería sustituir, o al menos integrar, la palabra «ministerio», que en nuestras lenguas recuerda la idea de funcionario, por la del griego original, diakonia, que implica la idea de servicio. De hecho, el propio Jesús, refiriéndose a los que gobiernan a los pueblos, precisa: «No será así entre vosotros» (Mc 10, 42-44), pues él ha venido «no a ser servido sino a servir» (Mc 10,45); más aún, durante la última cena lava los pies a sus discípulos «para que hagáis lo mismo que yo he hecho con vosotros» (Jn 13, 1-17). Pablo dirá más tarde que «hay diversidad de diakonías pero uno es el Señor» (1 Cor 12, 5; 16, 15). También 1Pe, además de advertir sobre el riesgo de «enseñorearse/katakyrieúontes» del rebaño que se le ha confiado $(5,3)$, propone esta nítida exhortación: «Que cada uno, según el don/chárisma recibido, lo ponga al servicio/diakonoûntes de los demás como buenos administradores de la multiforme gracia/cháris de Dios» $(4,10)$. En efecto, el servicio sobre los ministerios debe reconducirse a la dimensión del servicio agápico, ya que éstos no tienen otra finalidad que la edificación de la Iglesia, el cuerpo de Cristo: puesto que es «el amor el que edifica» (1 Cor 8, 1), lo mismo ocurre con las diakonías que el Señor ha distribuido «para la edificación de la comunidad» (1 Cor 14, 12; 2 Cor 13, 10; 10, 8) ${ }^{50}$.

50. Sobre este tema, véase: I. Kitzberger, Bau der Gemeinde. Das paulinische Wortfeld oikodomē/(ep)oikodomein, Würzburg 1986. Véase también: E. E. Ellis, «Collaboratori, Paolo e i suoi», in G. F. Hawthorne, R. P. Martin, D. G. Reid (eds.), Dizionario di Paolo e delle sue lettere, Cinisello Balsamo 1999, 256-266. 


\section{BIBLIOGRAFÍA CITADA}

Aguirre Monasterio, R. (ed.), Pedro en la Iglesia primitiva, Estella 1991. -(ed.), Así empezó el cristianismo, Estella 2011.

Aune, D. E., La profezia nel primo cristianesimo e il mondo mediterraneo antico, Brescia 1996.

Bellia, G. - Garribba, D. (eds.), Carismi, diaconia e ministeri dal I al II secolo d.C., (Ricerche Storico-Bibliche»XXV/2), Bologna 2013.

Brown, R. E., Donfried, K. P., Reumann, J. (eds.), Pedro en el Nuevo Testamento, Santander 1976.

- La comunidad del discípulo amado, Salamanca 1987.

Cattaneo, E. (ed.), I ministeri nella chiesa antica, Milano 1997.

Charlesworth, J. H., The Beloved Disciple, Valley Forge PA 1995.

Clarke, A. D., A Pauline Theology of Church Leadership, London-New York 2008 .

Dal Covolo, E., «Laici e laicità nei primi secoli della Chiesa», Rassegna di teologia 37 (1996) 359-375.

Ellis, E. E., «Collaboratori, Paolo e i suoi», in G. F. Hawthorne, R. P. Martin, D. G. Reid (eds.), Dizionario di Paolo e delle sue lettere, Cinisello Balsamo 1999, 256-266.

Fusco, C. (ed.), Carisma e istituzione in movimenti e comunità ecclesiali, Città del Vaticano 2018.

Garcia Martinez, F. - Trebolle Barrera, J., Los hombres de Qumrán, Madrid 1993.

Gehring, R. W., Hausgemeinde und Mission. Die Bedeutung antiker Häuser und Hausgemeinschaften - von Jesus bis Paulus, Giessen 2000.

Gianotto, C., Ebrei credenti in Gesù, Milano 2012.

Grelot, P., La donna nel Nuovo Testamento, Cinisello Balsamo 1996.

Guijarro, S., Fidelidades en conflicto, Salamanca 1998.

- Jesús y los primeros discípulos, Estella 2007.

-El camino del discípulo, Salamanca 2015.

Harland, Ph. A. Associations, Synagogues, and Congregations. Claiming a Place in Ancient Mediterranean Society, Minneapolis 2003.

Hasenhüttl, G., Carisma, principio fondamentale per l'ordinamento della chiesa, Bologna 1973.

Hummel, R., Die Auseinandersetzung zwischen Kirche und Judentum im Matthäusevangelium, München $1966^{2}$.

Kitzberger, I., Bau der Gemeinde. Das paulinische Wortfeld oikodomē/(ep)oi kodomein, Würzburg 1986. 
Klauck, H.-J., Hausgemeinde und Hauskirche im frühen Christentum, Stuttgart 1981.

Lohfink, G., Gesù come voleva la sua comunità? La chiesa quale dovrebbe essere, Cinisello Balsamo 1987.

Luz, U., El evangelio según Mateo, II, Salamanca 1990.

M. Adinolfi, L'apostolato dei Dodici nella vita di Gesù, Cinisello Balsamo 1985.

Munzinger, A., Discerning the Spirits. Theological and Ethical Hermeneutics in Paul, Cambridge 2007.

Norelli, E., Ascensio Isaiae, II - Commentarius, Turnhout 1995.

Okland, J., Women in their Place. Paul and the Corinthian Discourse of Gender and Sanctuary Space, London-New York 2004.

Penna, R., «Gesù Cristo Salvatore: cristologia e sue implicanze missiologiche», in G. Colzani, P. Giglioni, S. Karotemprel (eds.), Cristologia e Missione oggi, Roma 2001, 364-372.

-«Solo l'amore non avrà mai fine. Una lettura di 1 Cor 13 nella sua pluralità di senso», in Id., L'apostolo Paolo. studi di esegesi e teologia, Cinisello Balsamo 1991, 223-239.

- «Anonimia e pseudepigrafia nel Nuovo Testamento. Comparativismo e ragioni di una prassi letteraria», in Id., Vangelo e inculturazione, Cinisello Balsamo 2001, 795-816.

-Carta a los Romanos. Introducción, versión y comentario, Estella 2013.

-Le prime comunità cristiane. Persone, tempi, luoghi, forme, credenze, Roma $2017^{2}$.

-«Il femminismo di San Paolo», in: Nuria Calduch-Benages (ed.), San Paolo e le donne, Milano 2019, 95-102.

-Un solo corpo. Laicità e sacerdozio nel cristianesimo delle origini, Roma 2020, 63-91.

Perkins, Ph., Peter, Apostle for the Whole Church, Edinburgh 2000.

Perrot, Ch., Après Jésus. Le ministère chez les premiers chrétiens, Paris 2000, 73-78.

Prinzivalli, E., «Donne e ministeri nella chiesa antica: Alcune osservazioni preliminari», Augustinianum 57 (2017) 5-17.

Richard, E., Jesus: One and Many. The Christological Concept of New Testament Authors, Wilmington 1988.

Schelkle, K. H., La Comunità di Qumran e la Chiesa del Nuovo Testamento, Roma 1970.

Schlosser, J., Il gruppo dei Dodici. Ritorno alle origini, Cinisello Balsamo 2013. 
Trebilco, P., Self-Designations and Group Identity in the New Testament, Cambridge 2012.

Vanhoye, A., I carismi nel Nuovo Testamento, Roma 2011.

Visonà, G., Didachè, insegnamento degli apostoli, Milano 2000.

Vögtle, A., «Donne e funzioni ecclesiali», in Id., La dinamica degli inizi. Vita e problemi della Chiesa primitiva, Milano 1991, 131-161.

Weber, M., Wirtschaft und Gesellschaft, Tübingen 1980.

Winter, B. W., Roman Wives, Roman Widows. The Appearance of New Women and the Pauline Communities, Grand Rapids MI / Cambridge UK 2003. 